07

\title{
Влияние активации на пористую структуру и деформационно-прочностные свойства биоуглерода на основе древесины бука
}

\author{
(C) В.В. Шпейзман ${ }^{1}$, Т.С. Орлова ${ }^{1}$, А.А. Спицын ${ }^{2}$, Д.А. Пономарев ${ }^{2}$, \\ Н.И. Богданович ${ }^{3}$, J. Martinez-Fernández ${ }^{4}$ \\ ${ }^{1}$ Физико-технический институт им. А.Ф. Иофффе РАН, \\ Санкт-Петербург, Россия \\ ${ }^{2}$ Санкт-Петербургский государственный лесотехнический университет, \\ Санкт-Петербург, Россия \\ ${ }^{3}$ Северный (Арктический) федеральный университет им. М.В. Ломоносова, \\ Архангельск, Россия \\ ${ }^{4}$ Dpto Fisica de la Materia Condensada-ICMSE Universidad de Sevilla, \\ Sevilla, Spain \\ E-mail: shpeizm.v@mail.ioffe.ru; orlova.t@mail.ioffe.ru
}

(Поступила в Редакцию 14 июня 2016 г.)

Исследовано влияние активации на размеры, удельные объем и поверхность пор в монолитном биоморфном материале, полученном карбонизацией древесины бука. Показано, что при оптимальном режиме активации нагретым до $970^{\circ} \mathrm{C}$ водяным паром суммарные объем и поверхность пор, определенные по кривым адсорбции, выросли в 20 и 18 раз соответственно. С использованием прецизионной интерферометрической методики получены кривые деформации в условиях одноосного сжатия при ступенчатом нагружении и измерена скорость деформации с шагом по перемещению $325 \mathrm{~nm}$ для активированных и неактивированных образцов. Несмотря на увеличение пористости, прочность и максимальная деформация образцов не уменьшились. Проанализировано поведение скачков скорости деформации в микро- и нанометровом диапазонах. Показано, что максимальный размер микрометровых скачков $(4 \mu \mathrm{m})$ хорошо коррелирует со средним размером возможной области деформации в образцах (средним расстоянием между порами малого размера), а минимальные размеры скачков деформации близки к размерам мезопор. Анализ изменения деформации и ее скорости при активации показывает, что влияние активации на деформационно-прочностные характеристики определяется нанометровыми дефектами, наиболее вероятными из которых являются микрои мезопоры.

Работа выполнена при частичной поддержке РФФИ (грант № 14-03-00496) и программы Президиума РАН $(\Pi-20)$

DOI: $10.21883 /$ FTT.2017.01.43959.242

\section{1. Введение}

Пористые биоморфные углеродные материалы, получаемые карбонизацией древесины или прессованной микрофибры, являются перспективными для различных практических приложений в электрохимии, энергетике и других областях современной техники. Благодаря наличию протяженной взаимосвязанной системы пор с жестким каркасом, которые могут быть заполнены полностью или частично металлами, полимерами, кремнием и др., эти материалы являются основой для создания разнообразных композитов и керамических соединений. Высокая пористость природных биоуглеродов позволяет рассматривать их в качестве возможных материалов для электродов электрохимических конденсаторов, поскольку они обладают большой площадью поверхности, высокими электропроводностью и удельной емкостью, контролируемыми размерами пор, подходящими для ионов электролитов, и электрохимически устойчивой поверхностью $[1-5]$. Для изготовления из них электродов не требуется связующих материалов, при этом рабочей поверхностью электрода является поверхность всего углеродного каркаса. Исследования, проведенные в [4,5], показали, что карбонизация с Ni- или Fe-содержащим катализатором позволяет существенно повысить удельную поверхность, а для образцов с температурой карбонизации $T_{\text {carb }} \sim 1000^{\circ} \mathrm{C}$ сохранить упругие свойства и слегка увеличить прочностные характеристики по сравнению с характеристиками образцов, карбонизированных без катализатора. Другим известным способом повышения удельной поверхности углеродных материалов является их активация, т.е. обработка водяным паром или специальным химическим реагентом. Активированный уголь широко применяется в медицине, а также в химической, пищевой и других отраслях промышленности для очистки, разделения и извлечения различных веществ. В настоящей работе исследовалось влияние активации на удельную поверхность, основную часть которой составляет поверхность пор нанометровых размеров, и на деформационно-прочностные характеристики биоморфного материала, полученного карбонизацией древесины бука. 


\section{2. Образцы и методика исследования}

Исследовались образцы биоуглерода, полученного карбонизацией дерева бука (Fagus silvatica) при температуре $T_{\text {carb }}=1000^{\circ} \mathrm{C}$. В качестве исходного материала были выбраны куски древесины размером $75 \times 15 \times 15 \mathrm{~mm}$, предварительно высушенные в печи для удаления из пор остаточной влаги, чтобы предотвратить возникновение трещин в процессе последующего пиролиза. Процесс пиролиза осуществлялся в потоке инертного газа (азота чистоты 99.999\%). Нагрев проводился со скоростью $1{ }^{\circ} \mathrm{C} / \mathrm{min}$ до $500^{\circ} \mathrm{C}$, затем со скоростью $5{ }^{\circ} \mathrm{C} / \mathrm{min}$ до температуры $T_{\text {carb }}$, при которой заготовки для образцов выдерживались в течение $30 \mathrm{~min}$ и затем охлаждались со скоростью $5^{\circ} \mathrm{C} / \mathrm{min}$, после чего из них были изготовлены образцы размером $5 \times 5 \times 10 \mathrm{~mm}$.

Активация образцов проводилась при следующих условиях: активирующий агент - водяной пар, температура активации $970{ }^{\circ} \mathrm{C}$, продолжительность активации при заданной температуре от 1 до $15 \mathrm{~min}$. Образцы биоуглерода массой около $0.2 \mathrm{~g}$ помещались в трубчатый вращающийся реактор с сетчатой перегородкой, частота вращения $1 / 60 \mathrm{~Hz}$. Реактор с образцами помещался в трубчатую печь и продувался водяным паром. Продолжительность нагрева до $970{ }^{\circ} \mathrm{C}$ составляла $3 \mathrm{~min}$. После нагрева реактора до заданной температуры производился отсчет времени активации. После окончания заданного времени активации подача пара прекращалась, и охлаждение реактора проводилось на воздухе.

Скорость изменения массы образцов при их активации (степень обгара) велика в самом начале процесса: после времени активации $t=1 \mathrm{~min}$ уменьшение массы образца составляло $\sim 18 \%$. Затем скорость изменения массы падает. Увеличение продолжительности обработки паром свыше $15 \mathrm{~min}$ вызывало в большинстве случаев растрескивание образца. В качестве характеристики интенсивности активации было выбрано относительное изменение массы образца. Исследования проводились на образцах с изменением массы после активации 15.0, 19.6 и $31.3 \%$. Для сравнения привлекались исходные образцы, не проходившие активации.

Характеристики сорбционной способности исходных и активированных образцов определялись по стандартным методикам измерения сорбционной активности по иоду и индикатору метиленовому голубому. Сорбционная способность по иоду активированных образцов возрастает с увеличением продолжительности процесса активации от 6.3 до $26.7 \%$, а по индикатору метиленовому голубому отсутствует или лежит в пределах статистической погрешности.

Анализ пористой структуры проводился методом низкотемпературной адсорбции азота на анализаторе удельной поверхности и пористости ASAP $2020 \mathrm{mpi}$ (Micromeritics, USA) на кафедре химии и химической технологии Северного (Арктического) федерального университета им. М.В. Ломоносова. Образцы предварительно дегазировали с помощью порта дегазации прибора при $25^{\circ} \mathrm{C}$ до остаточного давления $5 \mu \mathrm{m}$ ртутного столба с выдержкой при заданных условиях в течение $2 \mathrm{~h}$. Навеска образца составила $0.03 \mathrm{~g}$. По полученным изотермам адсорбции-десорбции с помощью программного обеспечения прибора рассчитывались параметры пористой структуры для исходных образцов и образцов с изменением массы в результате активации $19.6 \%$.

При определении механических свойств образцов использовалось ступенчатое нагружение сжатием со следующими параметрами: высота ступеньки напряжения $\Delta \sigma \sim 1.4 \mathrm{MPa}$, продолжительность действия постоянных напряжений $\Delta t$ от 100 до $300 \mathrm{~s}$; скорость и величина деформации измерялись с помощью лазерного интерферометра на частоте $500 \mathrm{~Hz}$. Ступенчатые кривые напряжение-деформация $(\sigma-\varepsilon)$ и деформация-время $(\varepsilon-t)$ аппроксимировались плавными кривыми, по которым определялись разрушающее напряжение (прочность $\sigma_{f}$ ) и предельная неупругая $\left(\varepsilon_{\text {inelast }}\right)$ и полная $\left(\varepsilon_{\text {total }}\right)$ деформация в момент разрушения [6]. Прецизионное измерение скорости деформации с помощью интерференционной методики позволило определить не только величину прочности и предельной деформации, но и характеристики скачков скорости и величины деформации на микро- и нанометровом уровнях. Минимальные размеры нанометровых скачков сравнивались с характеристиками пористой структуры образцов, рассчитанными по изотермам низкотемпературной адсорбции азота для исходных и активированных образцов.

\section{3. Результаты экспериментов и их обсуждение}

На рис. 1 показаны сглаженные кривые деформации $(\sigma-\varepsilon)$ при одноосном сжатии для неактивированных (кривая 1) и активированных в течение различного времени образцов (кривые 2-4). Для образцов с ма-

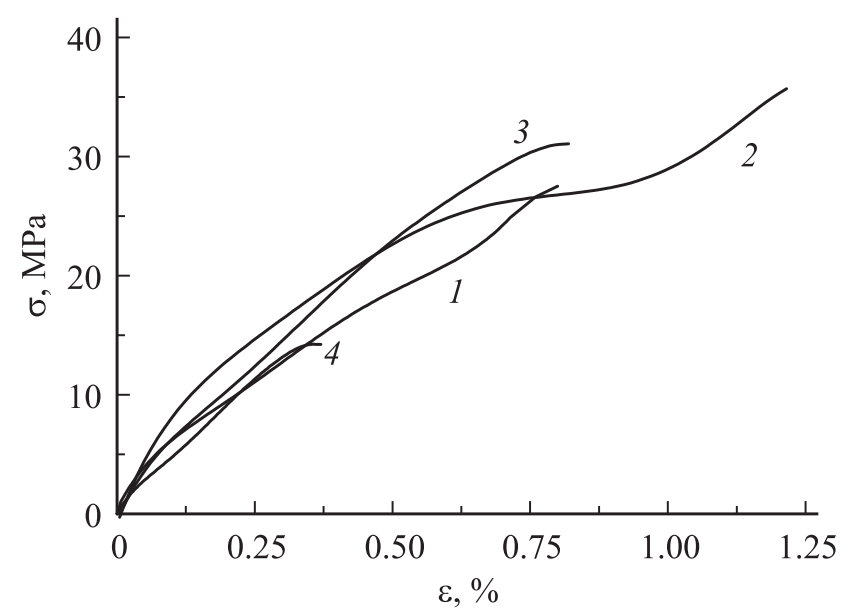

Рис. 1. Кривые деформации при сжатии исходного (1) и активированных образцов биоуглерода на основе бука с потерей массы при активации 15 (2), 19.6 (3) и 31.3\% (4). 
Таблица 1. Прочность, полная и неупругая деформация перед разрушением и характеристики скачков деформации при сжатии исходного и активированного биоуглерода

\begin{tabular}{|c|c|c|c|c|c|c|c|}
\hline $\begin{array}{c}\text { Потеря массы } \\
\text { при активации, \% }\end{array}$ & $\sigma_{f}, \mathrm{MPa}$ & $\varepsilon_{\text {total }}, \%$ & $\varepsilon_{\text {inelast }} \%$ & $S_{\overline{\Delta \dot{\varepsilon} / \varepsilon}}$ & $S_{\overline{\Delta U / U_{0}}}$ & $L, \mu \mathrm{m}$ & $L_{1}, \mathrm{~nm}$ \\
\hline $\begin{array}{l}0 \text { (неактивиро- } \\
\text { ванный образец) }\end{array}$ & 27.5 & 0.75 & 0.44 & 0.067 & 0.082 & \multirow{4}{*}{$1-4$} & \multirow{4}{*}{$\begin{array}{c}150-200 \\
50-80 \\
10-30,1-3\end{array}$} \\
\hline 15 & 35.7 & 1.22 & 0.81 & 0.085 & 0.061 & & \\
\hline 19.6 & 31.1 & 0.82 & 0.47 & 0.111 & 0.069 & & \\
\hline 31.3 & 14.2 & 0.37 & 0.22 & 0.225 & 0.095 & & \\
\hline
\end{tabular}

лым временем активации (кривые 2,3) наблюдается небольшое увеличение максимальных напряжений по сравнению с неактивированными образцами. Пологий участок на кривой 2, очевидно, связан либо с кратковременным ускорением локализованной деформации, либо с ростом трещины, которая была заблокирована и не привела к разрушению образца. ${ }^{1}$ В образцах, полученных при большом времени активации, трещины образуются и растут уже при малых напряжениях (возможно, они зародились еще при активации), что приводит к раннему разрушению (кривая 4). Использованная в работе интерференционная методика измерения скорости деформации позволила обнаружить скачки скорости и величины деформации на ступенях нагрузки и определить характеристики скачков $[5,6]$. На рис. $2, a, b$ приведены экспериментальные значения (точки) и сглаженная кривая зависимости скорости деформации от изменения длины $\Delta l$ (по абсолютной величине) $\dot{\varepsilon}(\Delta l)$ на ступенях с напряжениями $\sim 20 \mathrm{MPa} \mathrm{для} \mathrm{исходного}$ и активированного с потерей массы $19.6 \%$ образцов. По зависимостям $\Delta \dot{\varepsilon} / \dot{\varepsilon}(\Delta l)$, показанным на тех же рисунках, рассчитывались характеристики неоднородности деформации: среднеквадратичное отклонение экспериментальных значений скорости деформации от усредненной кривой $S_{\overline{\Delta \dot{\varepsilon} / \dot{\varepsilon}}}$ и размер скачков деформации $L$ в микрометровом диапазоне изменения длины образца $\Delta l$. Аналогичные характеристики неоднородности деформации в нанометровом диапазоне $\Delta l-S_{\overline{\Delta U / U_{0}}}$ и $L_{1}$ соответственно - рассчитывались по отклонению формы биений на интерферограмме деформации от синусоиды с амплитудой $U_{0}$ [7]. Используя разномасштабные усреднения сигнала $U$, можно выделить скачки деформации размером от единиц до нескольких сотен нанометров. Примеры нанометровых скачков деформации разного размера приведены на рис. 3. Величина прочности исходных и активированных образцов, их полная и неупругая деформация перед разрушением, а также характеристики неоднородности деформации приведены в табл. 1.

\footnotetext{
1 Заметим, что при нагружении с плавным или ступенчатым возрастанием напряжений проскакивание трещины приводит к появлению участков на зависимости $\sigma-\varepsilon$, близких к горинзонтали, в отличие от кривых, полученных при постоянной скорости деформирования, на которых подобные участки представляются в виде вертикальных срывов.
}

Как следует из рис. 2 и табл. 1, размеры микрометровых скачков не изменились при активации биоуглеродных образцов: средний размер составляет $\sim 2 \mu \mathrm{m}$, а интервал наблюдаемых в эксперименте размеров скачков составляет от 1 до $4 \mu \mathrm{m}$, причем нижний предел определяется возможностями методики, а верхний пористой структурой образца. В [8] было показано, что пористая структура биоуглеродных образцов древесины бука в микрометровом диапазоне подобна для всех
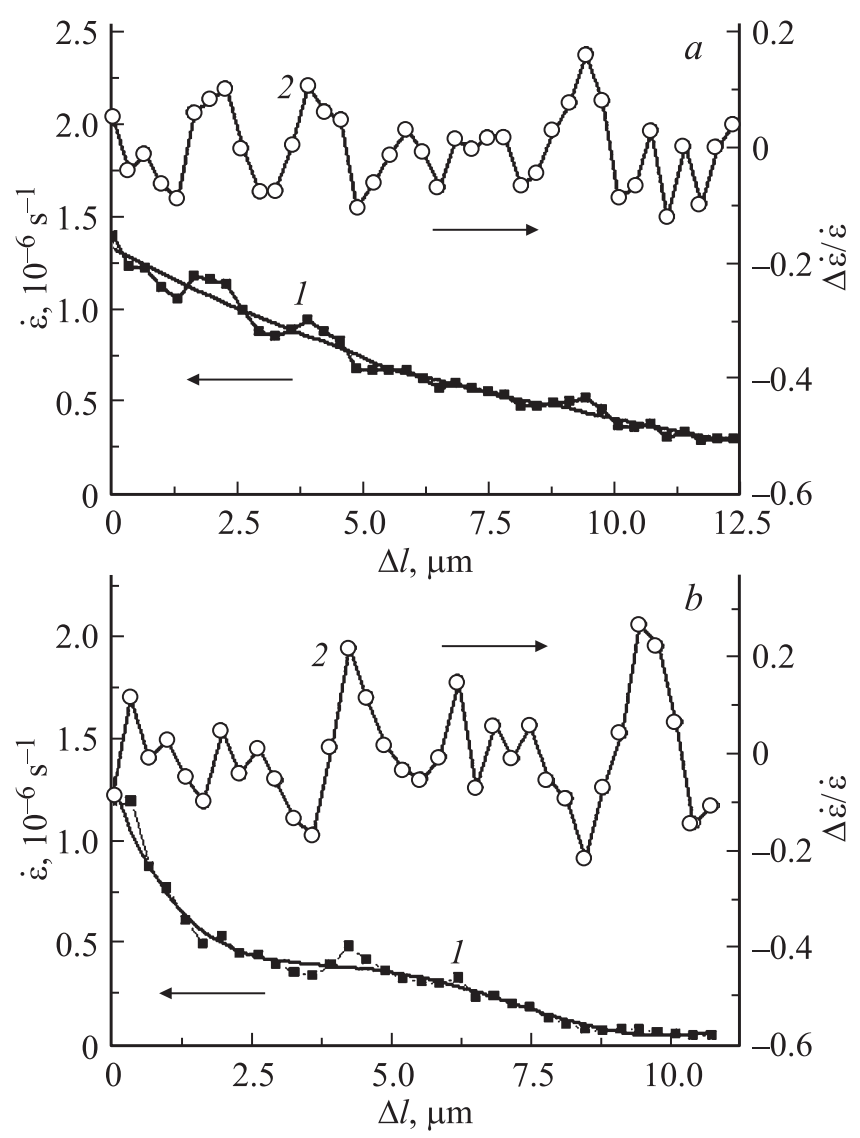

Рис. 2. Зависимость скорости деформации (1) и относительной разницы между ее экспериментальными значениями и усредненной кривой (2) от изменения длины при сжатии неактивированных образцов биоуглерода на основе бука $(a)$ и образцов, активированных с потерей массы $19.6 \%(b)$. 

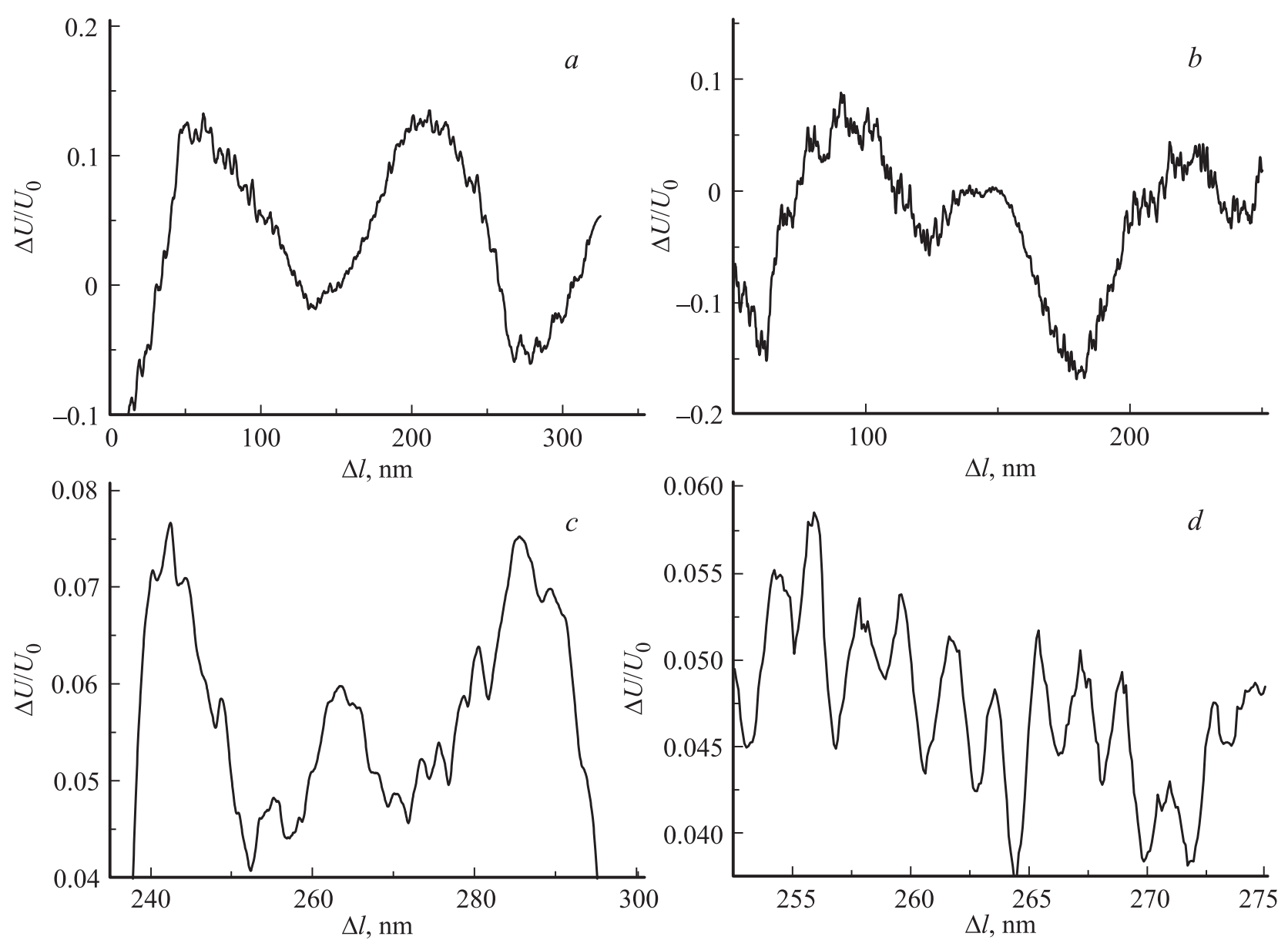

Рис. 3. Нанометровые скачки деформации различных размеров $L_{1}, \mathrm{~nm}$ (в скобках потеря массы при активации, \%): $a-160$ (19.6), $b-50$ и 80 (0, неактивированный), $c-20$ (31.3), $d-2(15)$.

температур карбонизации и характеризуется наличием пор малого $(3-7 \mu \mathrm{m})$ и большого $(22-38 \mu \mathrm{m})$ диаметров, ориентированных вдоль направления роста дерева. Типичная картина расположения пор двух характерных размеров приведена на рис. 4. Видно, что расстояние между большими порами может быть разным: от нуля, когда они соприкасаются, до $20-30 \mu \mathrm{m}$; между центрами малых пор среднее расстояние составляет $\sim 7 \mu \mathrm{m}$, между их краями $\sim 4 \mu \mathrm{m}$. Пространство между большими порами заполнено мелкими порами. Микродеформация в биоуглеродных образцах, очевидно, не затрагивает конфигурацию пор и ограничена пространством между ними. Полученный нами максимальный размер микрометровых скачков $(4 \mu \mathrm{m})$ хорошо коррелирует со средним размером возможной области деформации в образцах.

Среднеквадратичное отклонение $S_{\overline{\Delta \dot{\varepsilon} / \varepsilon}}$ растет с увеличением времени активации (потери массы образца), что можно связать с увеличением макроскопической пористости при активации (небольшим по сравнению с исходной), вызывающей увеличение амплитуды скачков скорости деформации (cp. рис. $2, a$ и $2, b$ ) при неизменной величине деформации в скачке. Так, если исходная объемная пористость составляла $60 \%$, то после актива- ции с потерей веса $\sim 20 \%$ твердый каркас стал занимать не $40 \%$ объема, а $32 \%$. Следовательно, пористость стала $68 \%$, т. е. увеличилась на $8 \%$.

В биоуглеродных материалах наноструктура представляет особый интерес, поскольку с порами малых размеров связаны большая удельная поверхность и удельная

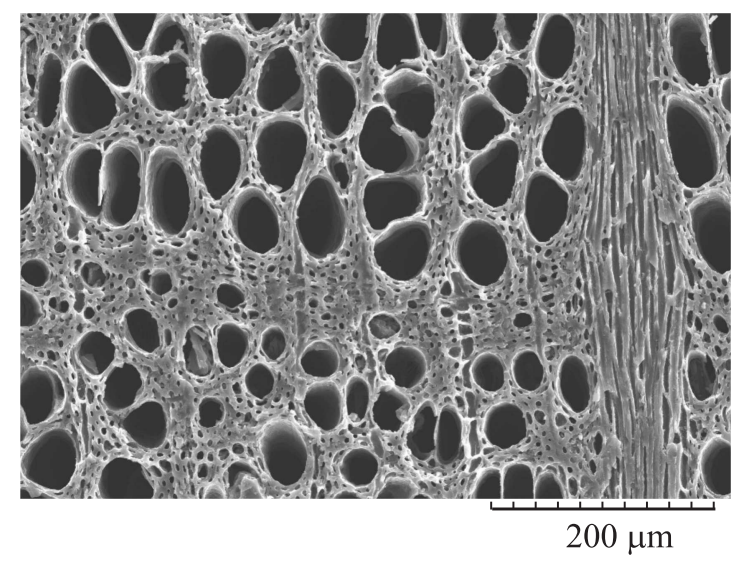

Рис. 4. Типичная морфология пор в образцах биоуглерода на основе бука. 
электроемкость этих материалов, которые определяют перспективу их применения в различных областях техники. Как показал анализ нанометровых скачков деформации, их размеры варьируются в широких пределах и могут быть собраны в четыре группы по 150-200, $50-80,10-30$ и $1-3 \mathrm{~nm}$ (рис. $3, a-d$ ). Размер скачка деформации определялся как расстояние между ближайшими максимумами зависимости разницы между экспериментальными значениями сигнала и его теоретической (синусоидальной) зависимостью, нормированной на амплитуду сигнала $\Delta U / U_{0}$, от изменения длины образца. Существенной разницы в размерах нанометровых скачков деформации в неактивированных и активированных образцах замечено не было. Однако среднеквадратичное отклонение $S_{\overline{\Delta U / U_{0}}}$, измеренное в интервале $\Delta l=325 \mathrm{~nm}$, что соответствует одному биению на интерферограмме, уменьшается с ростом интенсивности активации до его средних значений (потери массы 15 и 19.3\%) и возрастает при активации до 31.3\% потери массы (табл. 1). Аналогичная характеристика микрометровых скачков $S_{\overline{\Delta \dot{\varepsilon} / \dot{\varepsilon}}}$ монотонно возрастает с ростом потери массы при активации. Сравнение изменения $S_{\overline{\Delta \dot{\varepsilon} / \varepsilon}}$ и $S_{\overline{\Delta U / U_{0}}}$ при активации с характеристиками прочности и деформации показывает, что $S_{\overline{\Delta U / U_{0}}}$ в отличие от $S_{\overline{\Delta \dot{\varepsilon} / \dot{\varepsilon}}}$ коррелирует с величиной прочности и предельной деформацией. Поскольку указанные среднеквадратичные отклонения характеризуют соответствующие масштабу колебания скорости деформации, можно полагать, что влияние активации на деформационно-прочностные характеристики определяется нанометровыми дефектами. Возможно, ими являются нанометровые поры, на поверхности которых под действием нагрузки возникают очаги деформации.

Для исследования пористой структуры были выбраны активированные образцы с потерей массы 19.6\%, показавшие оптимальные деформационно-прочностные свойства, и неактивированные образцы для сравнения. На рис. 5, $a, b$ показаны изотермы низкотемпературной $(77 \mathrm{~K})$ адсорбции-десорбции азота для исходного (рис. 5, $a$ ) и активированного (рис. 5,b) биоуглеродных образцов в координатах удельный объем адсорбированного (1) и десорбированного (2) азота $V\left(\mathrm{~N}_{2}\right)$ относительное давление $P / P_{0}$, где $P_{0}$ - давление насыщенных паров азота над гладкой поверхностью. Расчет удельных объема и поверхности пор по изотермам адсорбции проводился с использованием метода BET (Brunauer-Emmett-Teller) [9] и принятой Международным союзом по теоретической и прикладной химии (IUPAC) классификации пор по их размерам: микропоры - до $2 \mathrm{~nm}$, мезопоры - от 2 до $50 \mathrm{~nm}$, макропоры - более $50 \mathrm{~nm}$. Границы между порами разной величины могут слегка изменяться в зависимости от особенности методики расчета удельных объема и поверхности пор и вида изотерм адсорбции. В табл. 2 приведены результаты расчета средней ширины пор, объема и удельной поверхности микро- и мезопор, а также суммарных объема и удельной поверхности пор, определяемых по изотермам адсорбции. Ширина щелевых пор
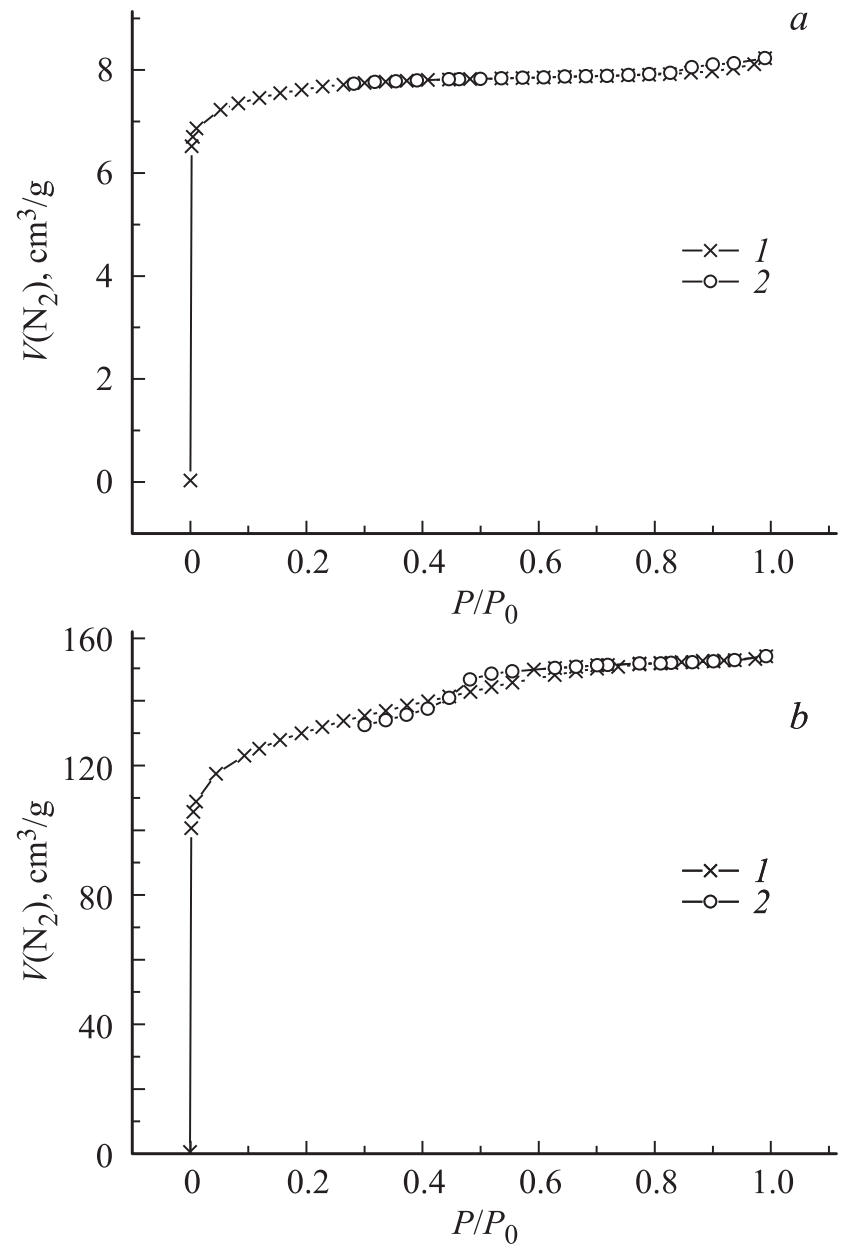

Рис. 5. Изотермы абсорбции (1) и десорбции (2) азота для исходного $(a)$ и активированного $(b)$ биоуглеродных образцов.

рассчитывалась методом HK (Horvath-Kawazoe) [10], a объем и удельная поверхность мезопор (1.7-50 nm) методом ВЈH (Barrett-Joyner-Halenda) [11]. Использовались также стандартный метод STSA (statistical thickness surface area) [12] и описанный в [13] метод ВВ (Broekhoff-de Boer).

Расчеты характеристик пористой структуры показали, что средний размер пор, определенный методом НК, практически не изменяется при активации, а удельные объем и поверхность значительно увеличиваются. Так, суммарный объем пор вырос в 20 раз, а их поверхность - в 18 раз, для мезопор в 100 и 60 раз соответственно. Основной вклад в объем и поверхность образца вносят микропоры (до $\sim 2 \mathrm{~nm}$ ), причем при активации их доля уменьшается, а доля мезопор возрастает с 4-5 до 14\% как для поверхности, так и объема. Характеристики пористой структуры, рассчитанные по разным моделям, могут слегка различаться (табл. 2), но это не меняет тенденции их изменения при активации. Полученные для активированного образца размер, удельные объем и поверхность пор, рассчитанные по изотермам адсорбции, близки к аналогичным характеристикам неак- 
Таблица 2. Расчетные данные, полученные при обработке изотерм

\begin{tabular}{|c|c|c|c|c|c|c|c|}
\hline \multirow{2}{*}{ Характеристика } & $\begin{array}{c}\text { Средняя } \\
\text { ширина пор }\end{array}$ & \multicolumn{2}{|c|}{$\begin{array}{c}\text { Объем } \\
\text { микропор }\end{array}$} & $\begin{array}{c}\text { Объем } \\
\text { мезопор }\end{array}$ & $\begin{array}{l}\text { Суммарный } \\
\text { объем пор }\end{array}$ & $\begin{array}{c}\text { Удельная } \\
\text { поверхность пор }\end{array}$ & $\begin{array}{c}\text { Удельная поверхность } \\
\text { мезопор }(1.7-50 \mathrm{~nm})\end{array}$ \\
\hline & $\mathrm{nm}$ & \multicolumn{4}{|c|}{$\mathrm{cm}^{3} / \mathrm{g}$} & \multicolumn{2}{|r|}{$\mathrm{m}^{2} / \mathrm{g}$} \\
\hline Метод & \multicolumn{2}{|l|}{ HK } & $\begin{array}{c}\text { T-plot, } \\
\text { carbon black }\end{array}$ & $\begin{array}{c}\mathrm{BJH}, \\
\mathrm{BB}\end{array}$ & \multicolumn{2}{|r|}{ BET } & $\mathrm{BJH}$ \\
\hline До активации & 1.110 & 0.0115 & 0.0115 & 0.0005 & 0.0121 & 22.7 & 0.958 \\
\hline После активации & $\begin{array}{c}1.121 \\
2.32(\mathrm{BET})\end{array}$ & 0.194 & 0.165 & 0.053 & 0.238 & 410 & 58.6 \\
\hline
\end{tabular}

тивированных образцов биоуглерода на основе бука, карбонизация которых проводилась с Fе-содержащим катализатором [5]. Однако величина эффекта для площади поверхности пор, приведенная в [5] и в настоящей работе, различна из-за разных значений этой величины для исходных образцов, причина которых остается неясной. Возможно, это связано с особенностями образцов или использованием различных приборов для измерения характеристик пористой структуры. Также неясной является заманчивая возможность получения аддитивного эффекта от каталитической карбонизации и последующей активации.

Сравнение размеров пор и скачков деформации показывает, что две группы малых скачков (1-3 и 10-30 nm) близки к размерам микро- и мезопор. Другими элементами структуры в образцах биоуглерода, карбонизированного при $1000^{\circ} \mathrm{C}$, являются хаотически распределенные в аморфной матрице трехмерные осколки типа графита $(1.2 \mathrm{~nm})$ и двумерные типа графена $(2.4-2.6 \mathrm{~nm})$ [8]. В хрупких телах, какими являются все известные биоуглероды, микродеформация развивается вблизи разного рода границ раздела: внешней поверхности, поверхности каналов и пор, межфазных границ. Поэтому более высокие прочность и деформация активированных образцов, как и каталитически карбонизированных, может быть связана с большей величиной поверхности, основная часть которой приходится на микропоры. Это может привести к увеличению возможных очагов локализованной деформации и частичной релаксации напряжений.

\section{4. Заключение}

Полезные свойства древесного угля известны с античных времен. В XVIII веке для усиления его действия как адсорбента начали использовать активированный уголь, a в начале XX века было организовано промышленное производство активированного угля. В настоящее время активированный уголь в зависимости от назначения выпускается в виде частиц размером от долей миллиметров до нескольких миллиметров и имеет сорбционную активность по иоду до $\sim 70 \%$ и удельную поверхность пор до $\sim 1500 \mathrm{~m}^{2} / \mathrm{g}$. Эти показатели в несколько раз превышают достигнутые нами $\left(26.7 \%\right.$ и $410 \mathrm{~m}^{2} / \mathrm{g}$ соответственно). Однако если иметь в виду использование из- делий из активированного угля (например, электродов), то нужны большие размеры и необходимая прочность материала. Одним из путей получения крупных кусков угля является пиролиз естественных пород дерева. Такой биоуглеродный материал сохраняет каркас дерева и изначальную форму после пиролиза. Исследование связи прочности и структуры (пористости) показало, что при активации с потерей массы до $\sim 20 \%$ резко увеличивается удельная поверхность и сохраняется или даже слегка возрастает прочность. Полученные в работе результаты далеко не исчерпывают возможности повышения как удельной поверхности, так и прочности биоуглеродных материалов. Известно, что легирование (введение в каналы, образованные порами) кремнием или металлами повышает прочность, а использование катализаторов при карбонизации увеличивает удельную поверхность. Это свидетельствует о возможности улучшения характеристик древесных биоуглеродов.

\section{Список литературы}

[1] A.G. Pandolfo, A.F. Hollenkamp. J. Power Sources 157, 11 (2006).

[2] L. Zhang, X.S. Zhao. Chem. Soc. Rev. 38, 2520 (2009).

[3] M.T. Johnson, A.S. Childers, J. Ramirez-Rico, H. Wang, K.T. Faber. Composites Part A 53, 182 (2013).

[4] A. Gutierrez-Pardo, J. Ramirez-Rico, R. Cabezas-Rodriguez, J. Martinez-Fernández. J. Power Sources 278, 18 (2015).

[5] В.В. Шпейзман, Т.С. Орлова, Б.И. Смирнов, А. Gutierrez-Pardo, J. Ramirez-Rico. ФТT 58, 685 (2016).

[6] В.В. Шпейзман, Т.С. Орлова, Б.К. Кардашев, Б.И. Смирнов, A. Gutierrez-Pardo, J. Ramirez-Rico. ФTT 56, 522 (2014).

[7] В.В. Шпейзман, Н.Н. Песчанская. ФТТ 51, 1087 (2009).

[8] Л.С. Парфеньева, Т.С. Орлова, Н.Ф. Картенко, Н.В. Шаренкова, Б.И. Смирнов, И.А. Смирнов, Н. Misiorek, A. Jezowski, T.E. Wilkes, K.T. Faber. ФTT 52, 1045 (2010).

[9] S. Brunauer, P.H. Emmett, E. Teller. J. Amer. Chem. Soc. 60, 309 (1938).

[10] G. Horvath, K. Kawazoe. J. Chem. Eng. Jpn. 16, 470 (1983).

[11] E.P. Barrett, L.G. Joyner, P.P. Halenda. J. Am. Chem. Soc. 73, 373 (1951).

[12] ASTM standard test method for carbon black-total and external surface area by nitrogen adsorption. D6556-10 (2010).

[13] J.C.P. Broekhoff, J.H. de Boer. J. Catalys. 9, 8 (1967). 